\title{
Programa de Preparação para Aposentadoria em uma Empresa Pública de Pernambuco: da análise à proposta de implementação
}

\section{Program of Preparation for Retirement in a Public Company of Pernambuco: from the analysis to the proposal of implementation}

\author{
Anne Cristine Cavalcanti da Silva, \\ Centro Universitário FBV - UniFBV/Wyden - Brasil \\ annecavalcanti18@gmail.com \\ ORCID: 0000-0002-0212-4600 \\ Diogo Henrique Helal \\ Centro Universitário FBV - UniFBV/Wyden - Brasil \\ diogohh@yahoo.com.br \\ ORCID: 0000-0002-1784-0941
}

Submetido em 21/04/2019; Aprovado em 18/05/2019

\begin{abstract}
Resumo
Programas de preparação para aposentadoria (PPAs) são ações importantes no contexto da gestão da aposentadoria, uma vez que oportunizam a reflexão dos trabalhadores sobre o tema, bem como ações organizacionais sobre o fenômeno. Este artigo tem como objetivo discutir a gestão do PPA de uma empresa pública do estado de Pernambuco. Busca-se, ainda, apresentar uma proposta de implementação de PPA em organizações. Para tal, utilizou-se a abordagem qualitativa de pesquisa por meio de observação não participante, documentos e entrevistas. Foram entrevistados participantes do programa e profissionais de RH. Apesar de o PPA ser compreendido de forma positiva e eficiente pelos entrevistados, os resultados indicaram algumas limitações: necessidades de inclusão de etapas de sensibilização e avaliação periódica, de reforço da perspectiva processual da aposentadoria e vivência de grupo em todos os módulos, de participação da família e de funcionários aposentados e desligados da empresa. Por fim, este artigo apresenta, com base na experiência analisada e na literatura sobre o tema, uma proposta metodológica mais ampla para implementação de um PPA em organizações brasileiras, públicas e privadas.
\end{abstract}

Palavras-chave: Programa de Preparação para Aposentadoria; Aposentadoria; Recursos Humanos.

\begin{abstract}
Retirement preparation programs (RPPs) are important actions in the context of retirement management, since they offer the reflection of the workers on the subject, as well as organizational actions on the phenomenon. This article aims to discuss the management of the RPP of a public company of the state of Pernambuco. It is also intended to present a proposal for the implementation of a RPP in organizations. For this, the qualitative research approach was used through non-participant observation, documents and interviews. Program participants and HR professionals were interviewed. Although the RPP was understood positively and efficiently by the interviewees, the results indicated some limitations: needs for inclusion of stages of sensitization and periodic evaluation, reinforcement of the procedural perspective of retirement and group living in all modules, participation of the retired employees of the company. Finally, this article presents, based on the experience analyzed and the literature on the subject, a broader methodological proposal for the implementation of a RPP in Brazilian public and private organizations.
\end{abstract}

Key words: Retirement Preparation Program; Retirement; Human Resources.

\section{Introdução}

O aumento da expectativa de vida e a diminuição da taxa de natalidade são características comuns a vários países e trazem consigo importantes desafios para as políticas públicas e para as organizações (Miranda, Mendes, Silva, 2016).

Dados referentes ao Brasil indicam que, em 2017, a expectativa de vida era de 76 anos; 30,5 anos 
a mais, em comparação à década de 1940 (Instituto Brasileiro de Geografia e Estatística [IBGE], 2018). Estima-se que em 2030, o número de idosos no Brasil será superior ao de crianças e adolescentes em cerca de 4 milhões; diferença que aumentará para 35,8 milhões no ano de 2050 (IBGE, 2016). Tais projeções, sem dúvida, consolidam o fenômeno do envelhecimento no país, e assinalam a necessidade de ações públicas e privadas que atendam a este novo perfil etário.

Em tal contexto, o fenômeno da aposentadoria ganha destaque como algo a ser melhor problematizado e gerido, tanto pelos trabalhadores, quanto pelas organizações. Não se trata apenas de discutir propostas de reforma no sistema da previdência social, mas refletir, a partir de uma perspectiva psicológica e social, acerca do impacto da aposentadoria na vida das pessoas (Tavares, Neri, Cupertino, 2012). Destaque-se que a aposentadoria tende a representar uma ruptura com o mundo formal do trabalho, provocando, assim, uma readaptação da rotina e das prioridades da pessoa que se aposenta (Zanelli, Silva, Soares, 2010).

Diante desta realidade percebe-se a importância de programas que promovam a reflexão sobre a aposentadoria, e que permitam uma transição mais tranquila para esta nova fase da vida. Estudos indicam, contudo, que, em geral, tal preparação quando existe ocorre de forma não sistemática, sem programação ou objetivo específico (Camboim, Queiroz, Vasconcelos, Queiroz, 2011).

Para Zanelli et al. (2010, p.61), as organizações possuem papel central nesse processo: "a transição que ocorre na aposentadoria pode ser facilitada sobremodo quando se promovem situações ou vivências no contexto organizacional, enquanto a pessoa ainda executa as suas atividades de trabalho". Autores indicam ainda que tal preocupação por parte das organizações pode ser caracterizada como uma ação de responsabilidade social, além de trazer benefícios ao clima e a imagem organizacional (Associação Brasileira das Entidades Fechadas de Previdência Complementar [ABRAPP], 2004; Antunes, Soares, Silva, 2015; França \& Soares, 2009; Netto \& Netto, 2008; Wang \& Shultz, 2010).

No entanto, pesquisas recentes brasileiras apontaram que as empresas, de forma geral, e os profissionais de recursos humanos apresentam dificuldades em desenvolver e implantar práticas de gestão de pessoas para os profissionais com mais idade, a exemplo dos programas direcionados à preparação para aposentadoria (Cepelos, Tonelli, Aranha Filho, 2013; França et al., 2014). Por sua vez, publicações científicas sobre programas de preparação para aposentadoria ainda são escassas, conforme indicam Beerh e Bennet (2009); Wang e Shultz (2010); Lima e Helal (2013) e Leandro-França (2016).

Com vistas a contribuir com o debate sobre o assunto, o presente artigo tem como objetivo discutir a gestão do PPA de uma empresa pública do estado de Pernambuco. Busca-se, ainda, apresentar uma proposta de implementação de PPA em organizações públicas e privadas.

\section{Contexto da Realidade Investigada}

A pesquisa foi realizada numa instituição pública da administração indireta do estado de Pernambuco (PE), dotada de personalidade jurídica de direito privado, que tem o Estado como seu maior acionista e sede na capital, Recife. A organização possui mais de 45 anos de existência e opera em 174 dos 185 municípios do estado de PE. No momento da pesquisa (março a agosto/2018) contava com um quadro de 3.498 empregados (751 do sexo feminino e 2.747 do sexo masculino) e 2.392 terceirizados, compreendendo capital e interior.

No que diz respeito a sua identidade organizacional, a empresa tem como missão prestar serviços de forma sustentável por meio da conservação do meio ambiente, contribuindo para a qualidade de vida da população; e como valores, preceitos como: ética e disciplina; compromisso; integração, participação e valorização do capital humano; satisfação do cliente e modicidade tarifária; qualidade e produtividade; e responsabilidade social. Apresenta como um dos pilares de seu planejamento estratégico, na perspectiva da organização e relacionamento institucional, o desenvolvimento da organização e gestão da empresa; e a melhora da imagem organizacional.

Quanto à aposentadoria e seus desdobramentos, a organização oferece aos seus empregados públicos um plano de previdência complementar, cuja finalidade principal é suplementar, parcial ou totalmente, os benefícios da aposentadoria, seja por invalidez, por tempo de contribuição, por idade, aposentadoria especial ou pensão por morte. Disponibiliza também, por intermédio do Acordo Coletivo de Trabalho, um Plano de Incentivo à Aposentadoria (PIA) e possui um programa de preparação para aposentadoria, denominado de Programa Nova Vida.

O Nova Vida ocorreu, pela primeira vez, em 2010, sendo reformulado e implantado de fato em 
2016. Deste ano até março de 2018, foram realizadas 06 turmas, com um total de 117 empregados participantes, 43 mulheres e 74 homens. Do total de participantes, a maioria continuou trabalhando (88 empregados) e 29 de fato se aposentaram. 26 dos 117 estavam inscritos no PIA.

Acrescenta-se que no momento da presente pesquisa, 530 empregados da empresa, $15,15 \%$ do efetivo, encontravam-se em situação de proximidade com a aposentadoria, seja porque já estavam aposentados (235), embora continuassem trabalhando, ou porque já estavam aptos a se aposentar (295), considerando o tempo de contribuição apenas nesta instituição.

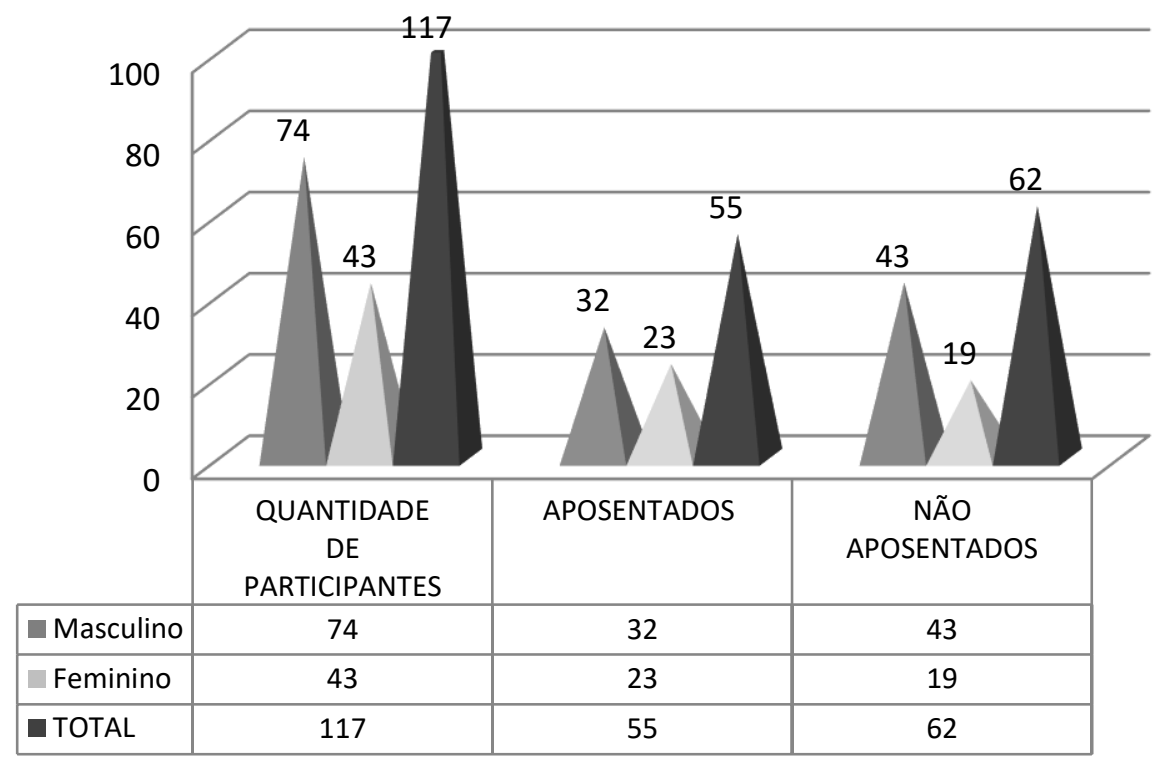

Figura 1. Perfil dos participantes do Programa Nova Vida (por sexo e situação de aposentadoria)

Fonte: elaborado pelos autores com base nas informações fornecidas pela empresa (2019).

Nota: Dos 55 participantes aposentados, 29 se desligaram da empresa.

\section{Diagnóstico da Situação-Problema}

A organização estudada apresenta uma quantidade considerável de empregados já aposentados e ainda na ativa, ou com tempo de contribuição para se aposentar. Essa característica, somada ao fato de que grande parte dos empregados inscritos no PIA hesitava em se desligar da organização, a fez optar pela implantação do PPA, o qual pretendia incentivar os já aposentados a se desligarem da empresa.

Embora, o objetivo atual do programa esteja voltado para uma ação de valorização do empregado ao final da carreira, oportunizando novas possibilidades de atuação, há ainda receio de muitos empregados em participar, mesmo após grande esforço da área de RH em sua divulgação. Como se pode observar (Figura 1), verifica-se uma recusa na adesão ao programa, principalmente por parte dos já aposentados, assim como a permanência destes na organização mesmo após a realização do PPA.

Os profissionais de RH têm orgulho em conduzir tal programa; defendem a sua permanência, apesar da falta de investimentos, da instabilidade de permanência dos dirigentes organizacionais, e dificuldade de adesão. Parecem, porém, não saber ao certo como colocar em prática suas ideias e concepções sobre PPA, perdendo a oportunidade de utilizar o Nova Vida como um importante instrumento para a gestão do conhecimento e o combate ao ageísmo.

Diante deste cenário, considerando as especificidades da organização, vê-se a necessidade de se analisar com mais detalhes, à luz da literatura acadêmica, e também sob a perspectiva dos trabalhadores, os pormenores do Nova Vida. 0 intuito é fornecer para a organização um diagnóstico do programa de forma a torná-lo mais eficiente tanto para a empresa quanto para os participantes.

Com essa finalidade, considerando a complexidade do fenômeno aposentadoria, este artigo optou por uma pesquisa qualitativa, por meio de realização de entrevistas em profundidade, analisadas pela técnica de análise de conteúdo (Bardin, 2000; Minayo, 1998). Documentos da organização que tratavam sobre sua história e sobre o Programa Nova Vida, assim como a observação não participante, realizada 
em março de 2018, na $7^{\circ}$ turma do PPA, no primeiro dia do programa, com base em um roteiro previamente elaborado, foram também instrumentos de coleta de dados.

As entrevistas, realizadas no período de dezembro de 2017 até março de 2018, aconteceram no ambiente organizacional dos entrevistados, selecionados por tipicidade e acessibilidade. Foram entrevistados dois profissionais de recursos humanos diretamente responsáveis pelo Programa (o gerente de RH e a psicóloga organizacional da empresa), e dezesseis funcionários aposentáveis ou aposentados participantes do Programa Nova Vida, sendo esse segundo grupo entrevistado até a saturação dos dados (Fontanella et al., 2011).

Temas relacionados à percepção sobre aposentadoria, a estrutura do programa de preparação, e investigações sobre os possíveis gaps e potencialidades do PPA serviram como base para a produção dos roteiros de entrevista, elaborados de forma específica para cada grupo de sujeitos.

0 tratamento e análise dos dados foram efetuados por meio da análise de conteúdo (Bardin, 2000), com categorias a posteriori, de acordo com a sequência explicitada a seguir: primeiro, houve a leitura prévia das entrevistas, que possibilitou a transformação dos dados brutos do texto em unidades de análise; segundo, a essas unidades foram incorporadas frases retiradas das entrevistas; terceiro, essas unidades de análise foram agrupadas sob um título cujo significado estivesse relacionado com as unidades de análise categorizadas; quarto, às frases foi atribuída a identificação do participante para que elas pudessem ser identificadas por entrevistado, caso o leitor assim o deseje (Bardin, 2000). Por fim, tais análises dos dados foram interpretadas à luz do referencial teórico adotado.

\subsection{Programa Nova Vida}

O Nova Vida apresenta como identidade visual uma árvore desenhada em cores suaves (ver Figura 2) que representaria, segundo a área de recursos humanos, a base da proposta principal do programa: dar um novo significado a aposentadoria. Essa ressignificação viria, segundo os profissionais de RH entrevistados, por meio de processos informativos e educativos, da promoção do autoconhecimento, da valorização das histórias de vida e dos potenciais individuais, e da construção de um planejamento de vida.

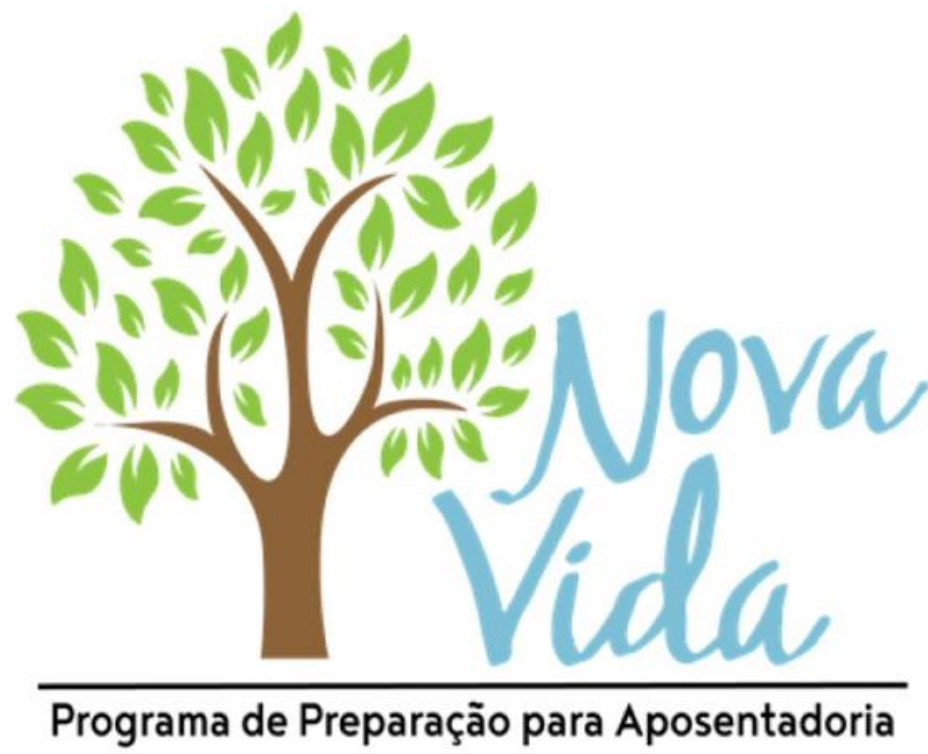

Figura 2. Logomarca do Programa Nova Vida

Fonte: Cedida pela área de Recursos Humanos da instituição (2018).

O objetivo geral do Nova Vida é, portanto, definido como um despertar para as mudanças biopsicossociais promotoras de uma melhor qualidade de vida dentro e fora do trabalho; e os objetivos específicos são direcionados para a redução de angústias causadas pelo processo de aposentadoria, promoção de subsídios para o desligamento do trabalho com a elaboração de um projeto de vida, e incentivo à busca por novos e contínuos aprendizados (ver Quadro 1).

Segundo os profissionais de RH e os informes sobre o programa, o PPA foi construído com base 
em quatro pilares (mental, financeiro, espiritual e social) que serviram como premissas tanto para a construção dos objetivos, quanto para a definição dos temas a serem trabalhados em cada módulo do programa.

Quadro 1 - Objetivo geral e específicos do Programa Nova Vida.

\begin{tabular}{|l|}
\hline \multicolumn{1}{|c|}{ Objetivo geral: } \\
\hline $\begin{array}{l}\text { Proporcionar aos empregados participantes um despertar para mudanças biopsicossociais que levem a uma } \\
\text { melhoria da qualidade de vida dentro e fora do ambiente de trabalho }\end{array}$ \\
\hline \multicolumn{1}{|c|}{ Objetivos específicos } \\
\hline $\begin{array}{l}\text { Minimizar angústias concernentes ao processo de aposentadoria de forma que, ainda dentro da organização, } \\
\text { percebam-se fora dela com confiança nas suas potencialidades; }\end{array}$ \\
\hline $\begin{array}{l}\text { Proporcionar subsídios para seu desligamento do trabalho, com estruturação de um projeto de vida que } \\
\text { permita novas formas de realização profissional, diferentes alternativas de trabalho e renda, bem como } \\
\text { satisfação pessoal; }\end{array}$ \\
\hline Estimular a busca por novos e contínuos aprendizados, a fim de que obtenham melhor qualidade de vida. \\
\hline
\end{tabular}

Fonte: Informe do Programa Nova Vida disponibilizado pela instituição (2018).

Em seu formato atual, o programa possui carga horária total de $26 \mathrm{~h}$ e acontece em 03 dias e meio de encontros consecutivos. Inicialmente realizado em local externo à empresa (em um hotel), passou a ser oferecido nas dependências da própria organização (em uma grande sala de treinamento) a partir do ano de 2018, por questões de custo. A adesão ao Programa é voluntária, conforme indicado pela literatura (França \& Soares, 2009), e o público alvo, que era inicialmente os empregados inscritos no Programa de Incentivo à Aposentadoria, foi ampliado, devido a dificuldades no fechamento das turmas, para aqueles que tinham possibilidade de se aposentar em até 5 anos.

O PPA estudado está agrupado em três fases distintas: palestras informativas, oficina para construção do projeto de vida e sessão de coaching individual (ver Quadro 2). As palestras informativas tomam a maior parte do Programa, com $21 \mathrm{~h}$; sendo seguidas pela oficina de construção do projeto de vida, com $4 \mathrm{~h}$, e sessão de coaching individual, com 50 minutos (sendo apenas a primeira sessão custeada pela empresa). A sessão de coaching individual é a única que não acontece consecutivamente aos encontros; sua realização se dá em um prazo máximo de geralmente 01 mês após os encontros em grupo.

A divulgação do programa é realizada por todas as plataformas de comunicação da organização: e-mail marketing, intranet, rádios e cartazes internos, com o objetivo de atingir todos os empregados da capital e do interior do estado. Por ser uma empresa com várias unidades anexas, há um esforço maior dos responsáveis na divulgação por meio de ligações e e-mail direcionados aos gestores, sendo ainda complementada pela divulgação boca a boca dos participantes.

Quadro 2 - Fases do Programa Nova Vida

\begin{tabular}{|c|c|c|c|}
\hline Fases & Módulos & Assuntos & $\begin{array}{l}\text { Carga } \\
\text { Horária }\end{array}$ \\
\hline \multirow{3}{*}{$\begin{array}{l}\text { Fase 1: Palestras } \\
\text { informativas }\end{array}$} & $\begin{array}{l}\text { Abordagem } \\
\text { psicossocial }\end{array}$ & $\begin{array}{l}\text { Desmistificando a aposentadoria: } \\
\text { - refletindo os aspectos psicossociais e culturais da } \\
\text { aposentadoria; } \\
\text { - A aposentadoria e as relações familiares; } \\
\text { - A longevidade e o novo perfil do brasileiro da } \\
\text { melhor idade; } \\
\text { - O autoconhecimento e desenvolvimento pessoal } \\
\text { como aliados desta nova fase da vida }\end{array}$ & $7 \mathrm{~h}$ \\
\hline & $\begin{array}{l}\text { Aspectos jurídicos e } \\
\text { financeiros }\end{array}$ & $\begin{array}{l}\text { - Associação dos aposentados da empresa; } \\
\text { - Funcionalidade da previdência privada; } \\
\text { - Gestão das finanças pessoais; } \\
\text { - Aposentadoria: a importância de construir o } \\
\text { futuro agora }\end{array}$ & $5 \mathrm{~h} 30 \mathrm{~min}$ \\
\hline & $\begin{array}{l}\text { Saúde e sexualidade } \\
\text { na maturidade }\end{array}$ & $\begin{array}{l}\text { - Sexualidade na maturidade; } \\
\text { - Maturidade: prevenção e cuidados com a saúde. }\end{array}$ & $4 \mathrm{~h} 15 \mathrm{~min}$ \\
\hline
\end{tabular}




\begin{tabular}{|c|c|c|c|}
\hline & $\begin{array}{l}\text { Oportunidades no } \\
\text { voluntariado e } \\
\text { empreendedorismo }\end{array}$ & $\begin{array}{l}\text { - Voluntariado; } \\
\text { - Como iniciar seu próprio negócio; } \\
\text { - Gestão das finanças pessoais. }\end{array}$ & $4 \mathrm{~h} 15 \mathrm{~min}$ \\
\hline $\begin{array}{l}\text { Fase 2: Oficina para } \\
\text { construção do } \\
\text { projeto de vida }\end{array}$ & $\begin{array}{l}\text { Construção de um } \\
\text { plano de ação focado } \\
\text { no pós-carreira }\end{array}$ & - Oficina: construindo um projeto de vida & $4 \mathrm{~h}$ \\
\hline $\begin{array}{l}\text { Fase 3: Sessão de } \\
\text { coaching individual } \\
\text { para } \\
\text { monitoramento do } \\
\text { projeto de vida }\end{array}$ & $\begin{array}{l}\text { Sessões individuais } \\
\text { de coaching de vida }\end{array}$ & $\begin{array}{l}\text { - Sessões de coaching (sendo a primeira custeada } \\
\text { pela empresa, e as demais pelo empregado caso ele } \\
\text { queira efetivamente fazer o processo de coaching) }\end{array}$ & $50 \mathrm{~min}$ \\
\hline
\end{tabular}

Fonte: elaborado pelos autores com base nas informações fornecidas pela empresa (2019).

No que concerne à avaliação do Nova Vida, a área de RH a realiza ao final de todo o programa, solicitando aos participantes que preencham um formulário cujos critérios de resposta variam de excelente a péssimo, com perguntas sobre a organização do evento, os palestrantes, e autoavaliação. Há ainda no questionário uma pergunta aberta sobre os pontos fortes e fracos do PPA.

Com base em Nunes (2015) e em Murta, Leandro-França e Barbosa (2014), é possível afirmar que a avaliação realizada pela empresa contempla apenas o processo e não o resultado, sendo baseada em um único aspecto: a reação. No entanto, cabe registrar a preocupação do facilitador do módulo da abordagem psicossocial em avaliar o entendimento pelos participantes do que estava sendo apresentado, numa tentativa de se rever em tempo real a forma de condução dos conteúdos. Tal questão, contudo, não emergiu, quando das entrevistas com os profissionais de RH da empresa estudada.

\section{Análise da Situação-Problema}

Diante da situação apresentada podem-se fazer algumas observações a respeito do significado da aposentadoria, bem como da elaboração e da condução do Programa de Preparação para a Aposentadoria estudado - Nova Vida. Não há como se idealizar um programa de preparação para aposentadoria sem uma concepção prévia sobre as representações sociais da velhice e da aposentadoria. A partir da fala dos profissionais de RH e pela forma como o programa é estruturado, apreende-se que a definição de aposentadoria definida pelo Nova Vida está alinhada à visão predominante do fenômeno (Denton \& Spencer, 2009): saída remunerada da força de trabalho, estando relacionado à velhice. Cumpre destacar que um dos módulos do PPA, o de abordagem psicossocial, traz a apresentação do tema longevidade e o novo perfil do brasileiro da "melhor idade", provocando nos participantes a reflexão sobre o perfil atual dos aposentados.

A aposentadoria é compreendida ainda pelos profissionais de RH como um processo de adaptação cujas decisões anteriores e posteriores ao evento influenciam na forma de vivenciá-lo (Beehr \& Bowling, 2013; Higo \& Williamson, 2009; Jex \& Grosch, 2013; Shultz \& Wang, 2011). É vista também como uma oportunidade de continuidade da carreira profissional, seja na própria área de atuação do indivíduo ou em outras experiências, por meio de resgate de antigos projetos ou do descobrimento de novas habilidades e potencialidades (Shultz \& Wang, 2011; Wang \& Shi, 2014; Zanelli et al., 2010), se caracterizando, portanto, como um momento de desenvolvimento pessoal.

Porém, apesar da compreensão dos profissionais de RH de que a aposentadoria é um processo, e não simplesmente uma tomada de decisão, como afirmam Berg e Bowling (2013); Higo e Williamson (2009); Jex e Grosch (2013); Shultz e Wang (2011), entre outros, percebe-se que o programa não consegue em sua totalidade contemplar esta perspectiva, tanto no que diz respeito aos critérios para ingresso no PPA (empregados inscritos no PIA ou que tenham no mínimo 05 anos para se aposentar), quanto no acompanhamento da trajetória pós-decisão.

Em uma perspectiva processual, a reflexão sobre aposentadoria deve ser feita ao longo da vida, e não apenas nos 5 anos prévios à aposentadoria. Igualmente, em tal abordagem, há a preocupação de se acompanhar o momento pós aposentadoria. Os resultados indicaram que, não obstante haver a proposição de construção de um planejamento de vida, não existe, por parte da organização, um acompanhamento efetivo dos participantes pós-programa, mesmo sendo esta uma demanda por eles apontada. 0 processo de coaching individual pode até ser considerado uma tentativa desta ação, mas por não ter continuidade (apenas uma sessão é financiada pela empresa) e por acontecer num espaço de tempo 
relativamente próximo ao fim do programa, não se apresenta de forma efetiva como um acompanhamento posterior à aposentadoria.

Esses resultados vão ao encontro de outros anteriores, como os apresentados por Pazzim e Marin (2016). Para esses autores, a maioria dos programas de preparação para aposentadoria no Brasil está direcionada para pessoas que tenham tempo de até 05 anos para se aposentar. Destaque-se, ainda, que a Política Nacional do Idoso (Lei n. 8842, 1994) e o Estatuto do Idoso (Lei n. 10.741, 2003) estimulam a preparação dos trabalhadores para a aposentadoria com antecedência mínima de 02 (dois) e 01 (um) ano, respectivamente, da concretude do evento.

Quanto aos módulos do Programa Nova Vida, estes se assemelham ao formato sugerido pela literatura, com módulos informativo e formativo (França, 2002; França \& Vaughan, 2008; Zanelli et al., 2010), sendo o primeiro composto pelo ciclo de palestras, e o segundo pela oficina de construção do projeto de vida e sessão de coaching. Por meio da observação não participante e da fala dos empregados entrevistados, observou-se também que os temas da abordagem psicossocial eram sempre seguidos por uma reflexão em grupo por meio de dinâmicas após sua apresentação, o que permitia a troca de experiência, expectativas e informações entre os empregados. Contudo, tal metodologia não pareceu ser possível em todos os módulos, apesar de os participantes terem colocado como extremamente relevante a oportunidade de interação com os colegas.

Os temas abordados durante os encontros são também similares aos propostos por Muniz (1996), França (2002), França e Vaughan (2008), França e Soares (2009), Soares, Luna e Lima (2010), Zanelli et al. (2010). Contudo, observa-se que alguns aspectos considerados na literatura como importantes em um PPA não estão contemplados no Nova Vida: participação da família e depoimentos de funcionários da organização já aposentados (França, 2002; França \& Vaughan, 2008; Zanelli et al., 2010).

Quanto à participação da família, durante o módulo observado pelos pesquisadores, um dos participantes expôs a necessidade de que a sua esposa também estivesse participando, já que, segundo ele, apenas a sua fala não a faria pensar ou refletir sobre os impactos da aposentadoria no relacionamento: "sinto falta da minha esposa não estar aqui. Como vou explicar tudo isso a ela? Se eu falar, ela é difícil, vai dizer que é coisa de velho". Em consonância com esse relato, autores recomendam a participação dos familiares em alguma fase do programa por entenderem o seu papel relacional na formação dos indivíduos e a importância deles na construção das expectativas quanto ao papel do aposentado (França, 2002; França \& Carneiro, 2009; Zanelli, et al., 2010).

Os mesmos autores destacam também a importância da participação de funcionários aposentados da empresa no PPA, com o objetivo de um compartilhamento de experiências e expectativas, o que não foi observado no Nova Vida. 0 programa apresentou apenas, por meio de reportagens em vídeo ou revistas, exemplos reais de pessoas aposentadas que reinventaram a sua forma de vida.

Na perspectiva da avaliação do programa, a empresa estudada se aproxima da realidade da maioria das experiências nacionais de PPA: a etapa de avaliação geralmente não ocorre de fato ao nível dos resultados do programa para a vida dos participantes (França et al., 2014). Observou-se que o Programa Nova Vida não possui uma avaliação periódica, conforme sugerido por França (2010) e nem um acompanhamento do aposentado mesmo após a sua saída da empresa (França \& Carneiro, 2009). No entanto, apesar da inexistência de uma avaliação dos resultados de forma sistemática, a responsável pela condução do Programa afirma perceber, na avaliação dos participantes logo após o PPA, e em momentos diversificados na empresa, a efetividade subjetiva e prática do Nova Vida nas mudanças de postura dos empregados participantes.

A etapa denominada por Murta et al. (2014) como avaliação das necessidades, por Zanelli et al. (2010) como pesquisa preliminar, e por França (2002) como diagnóstico de situação da clientela, também não aconteceu de forma sistematizada antes da implantação do Nova Vida. O programa piloto, realizado em 2010, que poderia até ser considerado como uma etapa inicial, não contribuiu de forma efetiva para esta proposta devido à perda das informações referentes a este momento, conforme relatado pelos profissionais de RH. Acredita-se que a realização de um diagnóstico preliminar à criação do programa, assim como de eventos de sensibilização como uma forma de divulgar o PPA, poderiam vir a diminuir as dificuldades de participação relatadas pelos coordenadores. Esta é uma etapa que eles consideram importantes, mas destacam que até o momento não conseguiram colocar em prática. Para exemplificar, dos 117 empregados participantes até o momento da pesquisa, apenas 26 estavam de fato inscritos no PIA.

Importante registrar que o Nova Vida, até o momento de realização desta pesquisa, não havia sido 
institucionalizado como uma política da área de recursos humanos da empresa. Como o programa de preparação para aposentadoria ainda é uma prática, mas não uma política de $\mathrm{RH}$, o investimento em recursos humanos e financeiros para sua execução parece ficar no mínimo necessário para que ele aconteça. Os dirigentes, aparentemente, ainda não entendem de fato a importância de um programa deste tipo para os empregados e para a empresa como um todo, e demonstram não enxergar o PPA como uma ação que vem fortalecer o papel de responsabilidade social da empresa. Tal realidade reflete no receio da descontinuidade do PPA apontado pelos profissionais de RH e também pelos participantes.

“[...] 0 programa não está institucionalizado. Ele funciona, mas não está como decisão da Diretoria toda a sua institucionalização". (RH2)

“O Programa é bom permanecer, né? Mas isso depende muito de Diretoria, de decisão de Diretoria. De repente outra Diretoria assume e não tem mais essa visão, e queira realmente se preocupar só com os empregados da ativa. Isso é muito por gestão, infelizmente tenho que dizer isso. Essa gestão teve essa preocupação." (P10)

Ainda neste tema, vê-se que a área de Gestão de Pessoas não consegue apresentar para a Diretoria a importância e efetividade do programa, por não possuir indicadores que consigam, por exemplo, objetivar os resultados advindos com o PPA. Esta fragilidade possivelmente está associada à falta de foco em resultados, que pode justificar o pouco investimento dado ao Nova Vida.

"Mas, assim, essa nova gestão veio com muito essa proposta de mostrar o que a gente faz, que é uma coisa que a gente não tem conseguido muito: criar indicadores, mostrar o percentual de atendimentos individuais, em grupo, palestras, tudo; quantas pessoas foram atendidas e mostrar para o Diretor porque até hoje a gente não conseguiu fazer isso de uma maneira muito efetiva, entendeu? [...]." (RH1)

0 apoio ainda pequeno da Diretoria, assim como as restrições financeiras e a dificuldades de maior adesão dos empregados foram relatados pelos coordenadores como dificuldades para a realização do PPA. Por sua vez, a parceria com profissionais voluntários e o conhecimento e manejo para a realização do programa pela principal responsável pela sua coordenação foram indicados como os aspectos facilitadores.

Outro dado interessante refere-se ao gênero dos participantes do Nova Vida (vide Figura 1): o percentual não reflete o de empregados masculino e feminino aptos a se aposentar ou já aposentados. 0 percentual de mulheres participantes no programa (36\%) é superior ao referente ao público-alvo feminino para participação (24\%). Isso indica que as mulheres foram mais responsivas ao convite em participar do Nova Vida. Tal resultado pode mostrar uma maior resistência a debater a aposentadoria, por parte dos homens. Griffin, Loh e Hesketh (2013) indicam que o gênero é uma variável que pode impactar no processo de aposentadoria, e que, por isso, deve ser considerada no desenvolvimento de programas de preparação.

\section{Proposta da Intervenção}

Nesta seção são apresentadas propostas de melhoria para o Programa Nova Vida, a partir de uma abordagem processual, evidenciadas na análise da situação atual do PPA descrita nas seções anteriores. $\mathrm{O}$ intuito é ajudar a empresa e seus profissionais de $\mathrm{RH}$ a estruturar um programa mais adequado às necessidades dos participantes e da organização, e que venha a impactar de forma efetiva o seu entorno (ambiente organizacional, funcionários, família e sociedade de forma geral).

Especificamente, apresenta-se também uma proposta de elaboração de um roteiro metodológico mais amplo para a implantação de um PPA em organizações brasileiras, com base na experiência analisada, e em estudos de França (2002), Zanelli et al. (2010) e Murta et al. (2014), vide figura 3.

Salienta-se que como base para as sugestões apresentadas está a recomendação de que a aposentadoria seja considerada como um processo, e não apenas como uma decisão, e também como um fenômeno influenciado por fatores dos contextos micro, meso e macrossociais, e não apenas como algo individual. Neste entendimento, a aposentadoria é vista como um caminho em construção, ao longo da vida, sendo também impactada por experiências e decisões que ocorreram na trajetória do indivíduo, dentro e fora da organização (Beehr \& Bowling, 2013; Higo \& Williamson, 2009; Jex \& Grosch, 2013; Shultz \& Wang, 2011; Szinovacs, 2013).

Atendo-se especificamente ao Nova Vida, seguem-se abaixo as recomendações de melhoria:

Quadro 3 - Recomendações de Melhoria ao Programa Nova Vida e Resultados Esperados 


\begin{tabular}{|c|c|}
\hline Ações Propostas & Resultados Esperados \\
\hline $\begin{array}{l}\text { Ação 1: Realização de uma pesquisa ou diagnóstico de } \\
\text { necessidades com os trabalhadores aposentáveis, } \\
\text { aposentados e trabalhadores jovens da empresa, a fim } \\
\text { de se entender como eles percebem o momento da } \\
\text { aposentadoria e quais temas gostariam de ouvir. }\end{array}$ & Maior adesão dos empregados ao Programa. \\
\hline $\begin{array}{l}\text { Ação 2: Realizar uma campanha de sensibilização dos } \\
\text { empregados para o tema. }\end{array}$ & Maior adesão dos empregados ao Programa. \\
\hline $\begin{array}{l}\text { Ação 3: Definir palestras ou rodas de conversa sobre } \\
\text { aposentadoria para os trabalhadores mais distantes da } \\
\text { aposentadoria uma vez que a aposentadoria deve ser } \\
\text { vista como um processo. }\end{array}$ & $\begin{array}{l}\text { Combate ao ageísmo, uma vez que os trabalhadores } \\
\text { mais jovens, e em sua maioria, distantes da } \\
\text { aposentadoria seriam também incluídos na reflexão } \\
\text { sobre o tema. }\end{array}$ \\
\hline $\begin{array}{l}\text { Ação 4: Definição de indicadores que possam retratar o } \\
\text { impacto do programa para o ambiente organizacional. } \\
\text { Para isso é necessário que haja uma definição da alta } \\
\text { direção da empresa sobre o que se deseja de fato com o } \\
\text { Nova Vida - que resultados e benefícios são almejados? }\end{array}$ & $\begin{array}{c}\text { Segurança para os profissionais de RH ao } \\
\text { planejarem o PPA. Acompanhamento efetivo dos } \\
\text { resultados. Institucionalização do Nova Vida como } \\
\text { Política de RH. }\end{array}$ \\
\hline $\begin{array}{c}\text { Ação 5: Nos módulos do programa acrescentar a } \\
\text { participação de empregados já aposentados da } \\
\text { organização, a fim de que exponham sua experiência } \\
\text { com a aposentadoria. } \\
\end{array}$ & $\begin{array}{c}\text { Contribuir para desmistificar a percepção quase } \\
\text { sempre negativa dos participantes sobre estar } \\
\text { aposentado e afastado de uma rotina laboral } \\
\text { vivenciada por tantos anos. }\end{array}$ \\
\hline $\begin{array}{l}\text { Ação 6: No módulo de abordagem psicossocial } \\
\text { acrescentar a participação de um membro da família. } 0 \\
\text { objetivo é fazer a família entender o seu papel no } \\
\text { acolhimento do aposentado. }\end{array}$ & $\begin{array}{l}\text { Fortalecer a rede de apoio do aposentado, uma vez } \\
\text { que a família é considerada a rede de suporte mais } \\
\text { importante na aposentadoria. }\end{array}$ \\
\hline $\begin{array}{l}\text { Ação 7: Em todos os módulos do programa realizar } \\
\text { vivências em grupo e trocas de experiências. }\end{array}$ & $\begin{array}{c}\text { Fortalecimento do grupo uma vez que eles mesmos } \\
\text { destacaram serem esses momentos um dos grandes } \\
\text { protagonistas do PPA. }\end{array}$ \\
\hline $\begin{array}{l}\text { Ação 8: Trabalhar em momentos diferentes o impacto } \\
\text { da aposentadoria por gênero. Ou fazê-los refletir sobre } \\
\text { isso, quando em grupo, ou até, inserindo-a numa } \\
\text { possível etapa de sensibilização. }\end{array}$ & $\begin{array}{l}\text { Atender às necessidades demandadas pelos } \\
\text { participantes que advém da questão de gênero, de } \\
\text { forma a melhorar a perspectiva já ministrada no } \\
\text { que diz respeito à dificuldade de adaptação do } \\
\text { homem à vida familiar, e até extrapolando-a, no que } \\
\text { se refere também às questões de saúde, finanças e } \\
\text { socialização. }\end{array}$ \\
\hline $\begin{array}{l}\text { Ação 9: Realizar uma avaliação de reação ao final de } \\
\text { cada módulo do programa e promover encontros } \\
\text { anuais de acompanhamento dos participantes } \\
\text { (verificar com a empresa se os aposentados desligados } \\
\text { também serão acompanhados. }\end{array}$ & $\begin{array}{l}\text { Avaliação contínua dos participantes e dos } \\
\text { resultados do Nova Vida, fortalecendo o conceito da } \\
\text { aposentadoria como um processo. }\end{array}$ \\
\hline $\begin{array}{l}\text { Ação 10: Estimular os empregados participantes a } \\
\text { compartilharem conhecimentos tácitos, acumulados, ao } \\
\text { longo do tempo, com os demais membros da equipe, e } \\
\text { ainda orientar o gerente de cada área, a provocar esse } \\
\text { compartilhamento em suas equipes. }\end{array}$ & $\begin{array}{l}\text { Preservação do conhecimento da empresa, e } \\
\text { estímulo à cultura de gestão do conhecimento. }\end{array}$ \\
\hline
\end{tabular}

Fonte: elaborado pelos autores com base nas informações fornecidas pela empresa (2019).

Também se recomenda uma maior aproximação da empresa a Associação dos Aposentados, a fim de, com ela, manter esta importante rede de apoio para os aposentados e realizar um efetivo e duradouro trabalho de combate ao ageísmo.

Quanto ao modelo metodológico para elaboração de um PPA sugerido por este artigo, recomendase primeiramente a preparação, de forma ampla, da equipe responsável pelo PPA, de maneira que ela tenha domínio, e, portanto, segurança ao lidar com o tema. Conteúdos que trabalhem a definição de aposentadoria, modelos teóricos para sua compreensão, impactos na vida dos sujeitos, formas e características dos programas de preparação são indicados para este momento.

Após esta etapa, sugere-se a realização de um diagnóstico da situação atual do quadro funcional da empresa quanto à proximidade da aposentadoria. Tal etapa serviria para indicar o quantitativo de empregados em cada situação e assim servir como base para a formatação do programa, respondendo a alguns questionamentos, tais como: qual o público-alvo do programa? Posso trabalhar com diferentes 
públicos? Como fazer isso? Como engajar os trabalhadores mais jovens e incentivá-los a também pensar sobre o assunto?

0 próximo passo, defendido pelo modelo refere-se ao levantamento das necessidades dos participantes, conforme sugerem Zanelli, Silva e Soares (2010) e França (2002). A avaliação das necessidades seria o conhecimento da realidade dos participantes antes da sua participação no programa, a fim de se identificar os seus medos e anseios sobre o tema, sendo um elemento essencial para o planejamento e a execução, uma vez que direcionaria o conteúdo a ser trabalhado e as reflexões que seriam estimuladas (Murta et al., 2014).

Por fim, e com base nos retornos obtidos nas etapas anteriores, sugere-se, finalmente, um Processo metodológico para elaboração de um Programa de Preparação para Aposentadoria, com todos os seus pormenores, tendo como objetivos amplos os resultados que se esperam do programa tanto para os participantes quanto para a organização, seja ela pública ou privada.

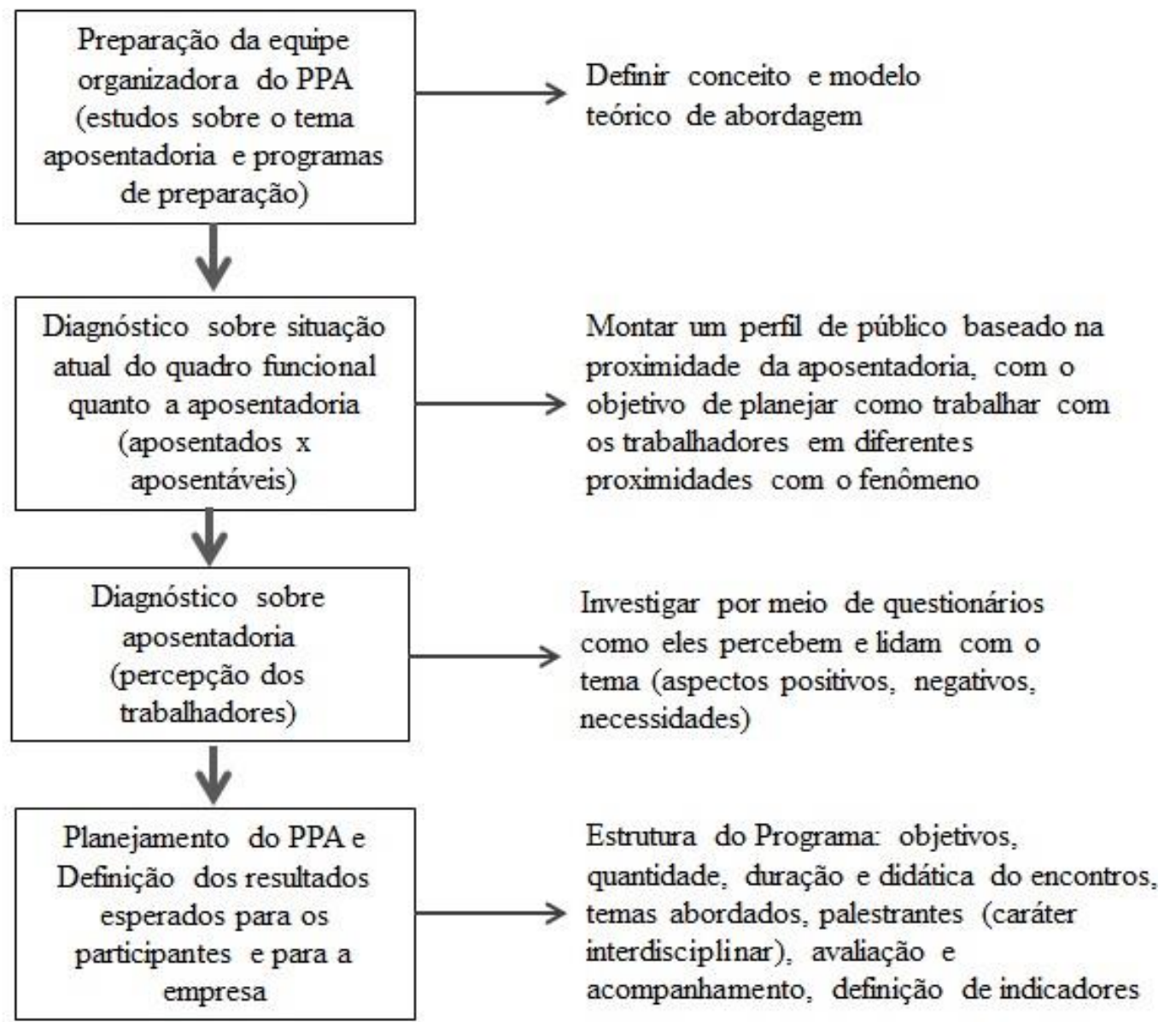

Figura 3. Processo metodológico para elaboração de um Programa de Preparação para Aposentadoria

Fonte: Elaborado pelos autores (2019).

\section{Conclusões e Contribuições Tecnológicas e Sociais}

A aposentadoria é um tema cada vez mais emergente, ganhando destaque nacional, a partir do aumento da longevidade, da diminuição da taxa de natalidade, e do debate sobre reforma da previdência. Os programas de preparação para aposentadoria (PPAs) são ações importantes neste processo na medida em que refletem o papel de responsabilidade social da empresa com os seus funcionários e oportunizam a reflexão dos trabalhadores sobre o tema, ajudando-os se preparar para esta experiência.

Por meio de uma investigação aprofundada do PPA de uma organização pública do estado de Pernambuco, o presente artigo teve como objetivo discutir a condução e gestão do PPA de uma empresa pública do estado de Pernambuco, e apresentar uma proposta de implementação de PPA em organizações, alinhado à sua política de Recursos Humanos. 
Observou-se que o Nova Vida, apesar de ser bem elaborado e adequado à realidade da organização, ainda não consegue trabalhar com uma visão mais ampliada da aposentadoria, seja por limitações de recursos financeiros ou por uma dificuldade em transformar as ideias e concepções dos responsáveis pelo programa em práticas no PPA. A falta de definição sobre o que a organização espera como resultado se apresenta como um importante limitador. Porém, apesar dessa e outras dificuldades, o Nova Vida é compreendido de maneira positiva e eficiente por ambos os grupos de entrevistados, e parece atender aos objetivos na medida em que indica influenciar os participantes na maneira de vivenciar o processo da aposentadoria.

Ainda como resultado desta pesquisa, apresenta-se um roteiro metodológico para elaboração de um PPA, com base em sugestões apresentadas na literatura, e na análise do programa estudado. Compreendendo a importância das variáveis contextuais na elaboração de uma ação de recursos humanos, vê-se a real necessidade de um bom planejamento antes de se colocar em prática uma ação desta complexidade.

Por fim, acredita-se que mais pesquisas sobre PPAs são necessárias, com vistas a contribuir com o conhecimento científico e empírico sobre o tema. 0 aumento da longevidade da população brasileira, e a mudança na concepção sobre o ser e estar aposentado impulsionam as empresas a entenderem que as suas responsabilidades com os profissionais ultrapassam as obrigações trabalhistas legalmente instituídas. À área de Recursos Humanos, por sua vez, é exigido um papel mais ativo neste processo, sendo de sua incumbência também a defesa de realização e da continuidade dos PPAs nas organizações, que pode ser fortalecida por meio de uma compreensão mais ampliada sobre o fenômeno da aposentadoria.

\section{Referências}

Associação Brasileira das Entidades Fechadas de Previdência Complementar. (2004). Aposentadoria com qualidade, responsabilidade social da empresa. Fundos de Pensão, 292 (23), 41- 44.

Antunes, M. H., Soares, D. H., \& Silva, N. (2015). Orientação para aposentadoria nas organizações: histórico, gestão de pessoas e indicadores para uma possível associação com a gestão do conhecimento. Perspectivas em Gestão \& Conhecimento, 5(1), 43-63.

Bardin, L. (2000). Análise de Conteúdo. São Paulo: Edições 70.

Beehr, T.A., \& Bennet, M.M. (2009). Examining retirement from a multi-level perspective. In: Shultz, K.S., \& Adams, G. A. (Ed.). Aging and work in the 21st century (pp.277-302). New York: Psychology Press.

Beehr, T. A., \& Bowling, N. A. (2013). Variations on a retirement theme: conceptual and operational definitions of retirement. In M. Wang (Ed.). The Oxford Handbook of Retirement (pp. 42-55). New York: Oxford University Press.

Camboim, V. S., Queiroz, J.V., Vasconcelos, N.V., \& Queiroz, F.C. (2011). Aposentadoria, o desafio da segunda metade da vida: estudo de caso em uma agência bancária. Revista Gestão Organizacional, 4(1).

Cepellos, V. M, Tonelli, M. J, \& Aranha Filho, J. E. (2013). Envelhecimento nas organizações: percepções e práticas de RH no Brasil. Anais do Encontro de Relações de Pessoas e Relações de Trabalho, Brasília, DF, Brasil, 4.

Creswell, J. W. (2010). Projeto de Pesquisa: métodos qualitativo, quantitativo e misto (3ํㅡㄹ. ed.). Porto Alegre: Artmed.

Fontanella, B.J., Luchesi, B. M., Saidel, M. G., Ricas, J., Turato, E. R. \& Melo, D. G. (2011). Amostragem em pesquisas qualitativas: proposta de procedimentos para constatar saturação teórica. Cadernos de Saúde Pública, 27(2), 389-394.

França, L. H. (2002). Repensando aposentadoria com qualidade: um manual para facilitadores de programas de educação para aposentadoria em comunidades. Rio de Janeiro: UERJ.

França, L. H., \& Carneiro, V. (2009) Programas de preparação para a aposentadoria: um estudo com trabalhadores mais velhos em Resende (RJ). Revista Brasileira de Geriatria e Gerontologia, 12(3), 429-447. França, L. H., \& Soares, D. H. P. (2009) Preparação para a aposentadoria como parte da educação ao longo da vida. Psicologia, Ciência e Profissão, 29 (4), 738-751.

França, L. H., \& Vaughan, G. (2008). Ganhos e perdas: atitudes dos executivos brasileiros e neozelandeses frente à aposentadoria. Psicologia em Estudo, 13 (2), 207-216, 2008.

França, L. H., Nalin, C. P., Brito, A. R., Amorim, S. M., Tangel, T., \& Ekman, N.C. (2014). A percepção dos gestores brasileiros sobre os programas de preparação para a aposentadoria. Estudos Interdisciplinares sobre o Envelhecimento, 19(3), 879-898. 
Griffin, B., Loh, V., \& Hesketh, B. (2013). Age, gender, and the retirement process. In: M. WANG, (Ed.). The Oxford Handbook of Retirement (pp. 202-214). New York: Oxford University Press.

Higo, M., \& Williamson, J. B. Retirement. (2009). In: D. Carr. e Gail (Firm) (Ed.). Encyclopedia of the life course and human development (pp. 328-336) Detroit: Macmillan Reference, 2009.

Instituto Brasileiro de Geografia e Estatística. (2017). Tábua completa de mortalidade para o Brasil 2016. Breve análise da evolução da mortalidade no Brasil.

Instituto Brasileiro de Geografia e Estatística. (2018). Tábua completa de mortalidade para o Brasil 2017. Breve análise da evolução da mortalidade no Brasil.

Jex, S. M., \& Grosch, J. (2013). Retirement decision making. In M. Wang (Ed.). The Oxford Handbook of Retirement (pp. 267-279). New York: Oxford University Press.

Lei Federal no 10.741 , de $1^{\circ}$ de outubro de 2003. Dispõe sobre o Estatuto do Idoso e dá outras providências. Recuperado de http://www.planalto.gov.br/ccivil_03/LEIS/2003/L10.741htm

Lei Federal, $n^{\circ}$ 8.842, de 04 de janeiro de 1994.Dispõe sobre a Política Nacional do Idoso, cria o Conselho Nacional do Idoso e dá outras providências. Recuperado de http://www.planalto.gov.br/ccivil_03/Leis/L8842.htm

Lima, T. B. \& Helal, D. H. (2013). Trabalho na terceira idade: uma revisão sistemática da literatura brasileira entre 2008 e 2012. Gestão e Sociedade, vol 7, n. 18, p. 369-394.

Minayo, M. C. (1998). O desafio do conhecimento: pesquisa qualitativa em saúde. São Paulo: Hucitec-

Abrasco.

Miranda, G. M. D., Mendes, A. C. G., \& Silva, A. L. A. (2016). 0 envelhecimento populacional brasileiro: desafios e consequências sociais atuais e futuras. Rev. Bras. Geriatr. Gerontol., Rio de Janeiro, 19 (3): 507-519.

Muniz, J. A. (1996). Programa de Preparação para o Amanhã. Revista Estudos de Psicologia, 2, 198 -204. Murta, S. G., Leandro-França, C., \& Barbosa, L. M. (2014). Pesquisa em avaliação de programas de educação para aposentadoria. In: S. G. Murta; C, Leandro-França; J, Seidl (Orgs). Programas de educação para aposentadoria: como planejar, implementar e avaliar. Novo Hamburgo: Sinopsys, p. 288-311.

Netto, F. S., \& Netto, J. P. (2008). Programa de preparação para a aposentadoria - PPA: responsabilidade social das organizações. Anais do XV Simpósio de Excelência em Gestão e Tecnologia, Resende/RJ, 15.

Nunes, C. 0. (2015). Programa de preparação de planos de vida para a aposentadoria: avaliação de necessidades, processos e efeitos. (Tese de Doutorado em Psicologia). Universidade Federal de São Carlos, São Carlos, Brasil. Recuperado de http://www.ppgpsi.ufscar.br/pdf/Tesecoatn_223235.pdf.

Pazzim, T. A, \& Marin, A. (2016). Programas de preparação para aposentadoria: revisão sistemática da literatura nacional. Revista Brasileira de Orientação Profissional 17(1), 91-101. Recuperado de http://pepsic.bvsalud.org/pdf/rbop/v17n1/10.pdf

Soares, D. H., Luna, I. .N, \& Lima, M. B. (2010). A arte de aposentar-se: programa de preparação para aposentadoria com policiais federais. Estudos Interdisciplinares sobre o Envelhecimento, 15, (2), 293313.

Shultz, K., \& Wang, M. (2011). Psychological perspectives on the changing nature of retirement. American Psychologist, 66(3), 170-179.

Szinovacs, M. E. (2013). A multilevel perspective for retirement research. In M. Waang (Ed.). The Oxford Handbook of Retirement (pp. 152-173). New York: Oxford University Press.

Tavares, S. S, Neri, A. L., \& Cupertino, A. P. (2012). Saúde emocional após a aposentadoria. In: A.L. Neri, \& M. S. Yassuda (Org.). Velhice bem-sucedida: aspectos afetivos e cognitivos. (pp. 91-110). Campinas, SP: Papirus.

Zanelli, J. C., Silva, N., \& Soares, D. H. P. (2010). Orientação para aposentadoria nas organizações de trabalho: construção de projetos para o pós-carreira. Porto Alegre: Artmed.

Wang, M, \& Shultz, K. S. (2010). Employee retirement: a review and recommendations for future investigation. Journal of Management, 36(1), 172-206. 